\title{
Recrutas da Alegria: Experiência em Humanização e Promoção de Saúde
}

\author{
Moraes, Ana Caroline Gomes; Souza, Jean Paulo Veronese de; Uhtra, Jardélli \\ Pires; Morrudo, Eduarda de Quadros; Susin, Lulie Rosane Odeh; Cost, Marilice \\ Magroski Gomes da
}

Universidade Federal do Rio Grande — aninhagmed@gmail.com

INTRODUÇÃO o Programa de extensão Recrutas da Alegria (RA) foi criado em 2011 por estudantes do curso de Medicina começou como um projeto para a semana da acolhida dos calouros do curso de Medicina, com uma intervenção pontual de estudantes no Hospital Universitário (HU) e, desde então, evoluiu para um programa que desenvolve um trabalho contínuo de atuação dividido principalmente em dois eixos: RA em Formação e RA em ação. no eixo RA em Formação são realizadas oficinas quinzenais de formação e reflexão dos extensionistas que visam o amparo da prática no hospital e surgem da compreensão das dificuldades que esta atividade impõe. Já o RA em ação compreende atividades semanais realizadas todos os sábados durante o período letivo e nas datas comemorativas no HU. Nessas atividades os extensionistas caracterizam-se como clowns e realizam atividades lúdicas, proporcionando amparo e alívio das ansiedades geradas nos pacientes pelo ambiente hospitalar. OBJETIVOS o Programa Recrutas da Alegria visa a promoção da saúde física e mental das pacientes internados no Pronto Atendimento, leitos da Enfermaria Pediátrica do Hospital Universitário e de outro hospital na mesma cidade além das crianças abrigadas em orfanatos, e idosos que vivem no Asilo do município, ao mesmo tempo em que busca formação de profissionais mais humanos e capazes de refletir criticamente sobre o meio em que estão inseridos, preparados para lidar não só de forma técnica, mas também de forma acolhedora, abrangendo o ser humano de forma integral. o programa trabalha a interdisciplinaridade entre musicistas, médicos, enfermeiros, psicólogos e artistas circenses, contribuindo dessa forma para a formação de profissionais comunicativos e capacitados para trabalhar em equipe. MÉTODOS Atualmente o Programa desenvolve visitas semanais ao HU e algumas intervenções pontuais em outros locais como na enfermaria pediátrica do outro hospital na mesma cidade, em orfanatos, e no Asilo do município, além de oficinas de preparação e encontros quinzenais com a participação de acadêmicos dos cursos de Medicina e Enfermagem. As intervenções semanais são realizadas por um grupo com aproximadamente sete alunos caracterizados como clowns, sendo que dentre estes estão um coordenador do programa, um relator e um músico. Durante as intervenções são realizadas atividades lúdicas e musicais. Após cada intervenção é feita uma relatoria que pretende avaliar as dificuldades e demandas do grupo. Os coordenadores e relatores se reúnem semanalmente para avaliar o projeto e desenvolver atividades que serão realizadas nas oficinas quinzenais com todos os participantes do grupo. Há também reuniões da coordenadoria com os psicólogos que apoiam o projeto visando debater as necessidades e desafios encontrados durante as intervenções e oficinas. RESULTADOS e DISCUSSÃO a interação entre o aluno de medicina e enfermagem com a pessoa hospitalizada contém uma rigidez disciplinar que exige que o estudante adote uma postura cordial, mas direta e direcionada às queixas dos pacientes, que resulta numa despersonalização do mesmo. a figura do clown promove uma quebra desse paradigma. na arte clownesca, da renovação cômica do conhecimento, sem 
limites, atravessando o outro lado do espelho, a outra margem do rio, virando o outro lado da moeda, encontrando o coração forte daqueles que dedicam suas vidas a criar personagens cômicos, que, desde os primórdios, têm como objetivo inverter a ordem préestabelecida, construindo uma "capacidade de parodiar" e de rir de situações humanas (WUO, 2009). Assim, através do clown os estudantes de medicina e enfermagem, percebem a realidade da pessoa hospitalizada com outro ponto de vista que considera as dimensões sociais e subjetivas do paciente. o seguinte relato exemplifica a contribuição do programa na relação entre o aluno e o paciente: "com o recrutas conseguimos chegar mais "perto" dos pacientes, conhecê-los e ajuda-los em todos os sábados que o recrutas se faz presente nas intervenções. Cada sábado que passa conseguimos nos "soltar" mais, nos dedicar mais(...)". O próximo relato também aborda a essa relação: "A principal mudança do RA é saber olhar nos olhos do paciente, mais do que o toque (o qual também considero essencial) o olhar conforta de uma maneira indescritível". Outro relato mostra a mudança na percepção do estudante sobre a realidade do paciente: "O RA permitiu ampliar minha visão sobre o doente e a compreensão de que o sofrimento físico acompanha o sofrimento mental intenso, necessitando esse último de auxílio e compreensão, por mais sutil que sejam". Além disso, o programa aborda durante suas oficinas quinzenais a experiência com a doença e as fases do luto, o próximo relato trata desse assunto: “(...) conseguimos enxergar como o paciente encara sua doença, e de que maneira isso afeta sua vida, e dessa forma, nós profissionais da saúde, conseguimos entender de que maneira agir em determinadas situações, como por exemplo, quando um paciente não é receptivo conosco, ou de difícil adesão a um tratamento, fato que pode refletir um problema pessoal. Isso com certeza acrescenta muito na nossa formação profissional e pessoal". o programa contribui para a formação do profissional de saúde humanista e preparado para trabalhar com outros profissionais buscando o bem estar do paciente e isso se evidencia na reflexão do extensionista: "Acredito que o Recrutas é uma oportunidade de se valorizar o trabalho dos diversos trabalhadores da área da saúde e permite a observação dos pacientes e do contexto da internação de forma mais completa, que não apenas as manifestações da doença que os acometem". Outro relato também aborda esse aspecto do programa: "O RA aproxima áreas que tinham que andar juntas como, medicina, enfermagem e psicologia, juntando as nossas sabedorias conseguimos lidar bem melhor com as situações, tanto cotidianas quanto nas intervenções que os recrutas da alegria realizam. e no caso das artes cênicas, que é essencial nas intervenções, acaba acrescentando conhecimento e habilidades para a nossa vida como um todo". CONCLUSÕES o programa Recrutas da Alegria segue os objetivos preconizados pelo Programa Nacional de Extensão Universitária, contribuindo na formação de um profissional de saúde humanista, que saiba refletir sobre o contexto social em que está inserido e que saiba se comunicar e trabalhar em equipe. Além disso, o aluno que participa do projeto tem a oportunidade de aprofundar seus conhecimentos sobre as dimensões sociais e subjetivas da pessoa hospitalizada, e dessa forma fortalecer o vínculo com o paciente.

Moraes, Ana Caroline Gomes; Souza, Jean Paulo Veronese de; Uhtra, Jardélli Pires; Morrudo, Eduarda de Quadros; Susin, Lulie Rosane Odeh; Cost, Marilice Magroski Gomes da. Recrutas da Alegria: Experiência em Humanização e Promoção de Saúde. In: Anais do Congresso Internacional de Humanidades \&

Humanização em Saúde [= Blucher Medical Proceedings, num.2, vol.1]. São Paulo: Editora Blucher, 2014. ISSN 2357-7282

DOI 10.5151/medpro-cihhs-10790 